\title{
$3^{\circ} \mathrm{SP} \bigcirc \mid \begin{aligned} & \text { 3 simpósio paranaense de } \\ & \text { patologia das construções }\end{aligned}$
}

ISSN 2526-7248 artigo n. 3SPPC1020, pp. 220-232, 2018

\section{Considerações a respeito das principais manifestações patológicas em pontes de concreto armado na cidade de Recife}

\author{
Pinheiro, Maria Rafaela de Almeida ${ }^{1}$; Silva, Emmanuel Inácio da ${ }^{2}$; Florencio, \\ Lutemberg de Araújo ${ }^{3}$. \\ ${ }^{1}$ Graduanda, Centro Universitário Uninassau, m.rafaelapinheiro@yahoo.com.br \\ ${ }^{2}$ Graduanda, Centro Universitário Uninassau, emmanuel.is@hotmail.com \\ ${ }^{3}$ Professor, Universidade de São Paulo, lutembergflorencio@yahoo.com,br
}

Resumo: O concreto armado é um dos materiais mais utilizados na construção civil, especialmente no Brasil. Sendo reconhecido por seu fácil manuseio, custo benefício e durabilidade. Porém, a falta de manutenção pode acarretar em problemáticas que afetam significativamente a vida útil das estruturas. A origem das manifestações pode ser atribuída às falhas construtivas ou de projetos, não somente à ausência de manutenção. Mas, fica claro que os problemas devem ser observados com antecedência e as devidas ações tomadas. Esse trabalho objetiva a apresentação das manifestações patológicas em pontes de concreto armado da cidade do Recife através de uma revisão bibliográfica dos trabalhos mais recentes. Consequentemente, realçar a importância de ações preventivas a fim de mitigar intervenções que acarretam alto custo ou, por se tratar de benfeitorias de uso comum da população, risco de danos severos à sociedade.

Palavras-chave: Infraestrutura, patologia das construções, concreto armado.

Abstract: Reinforced concrete is one of the most used materials in civil construction, especially in Brazil. Being recognized for its easy handling, cost benefit and durability. However, the lack of maintenance can lead to problems that significantly affect the life of the structures. The origin of the manifestations can be attributed to constructive or project failures, not only to the absence of maintenance. Although, it is clear that problems must be observed in advance and the actions taken. This work aims to present the pathological manifestations in reinforced concrete bridges of the city of Recife through a bibliographical review of the most recent works. Consequently, the implementation of preventive and mitigating actions of a high customary risk, for example, is a risk of serious harm to society.

Keywords: Infrastructure, construction pathology, reinforced concrete. 
PINHEIRO, M. R. A.; SILVA, E. I., CONSIDERAÇÕES A RESPEITO DAS PRINCIPAIS MANIFESTAÇÕES PATOLÓGICAS EM PONTES DE CONCRETO ARMADO NA CIDADE DE RECIFE. $3^{\circ}$ Simpósio Paranaense de Patologia das Construções (3० SPPC), artigo 3SPPC1020, pp. 220 - 232, 2018. DOI: 10.4322/2526-7248.020

\section{Introdução}

O concreto armado é um dos materiais mais utilizados na construção civil, especialmente no Brasil. Sendo reconhecido por seu fácil manuseio, custo benefício e durabilidade. Durante muito tempo acreditou-se que o concreto era um material praticamente eterno [1], mas essa premissa foi desacreditada à medida que as estruturas iam envelhecendo. Foi observado e comprovado que as estruturas de concreto precisavam ser acompanhadas e avaliadas para garantir a vida útil de projeto.

Ainda de acordo com Santos [1], a falta de manutenção é um dos fatores que mais influenciam para a baixa durabilidade do concreto, e como consequência o aparecimento de diversas manifestações patológicas. Diante desta realidade várias pesquisas são realizadas todos os anos com a finalidade de antever as possíveis manifestações e prolongar a vida útil dentro dos padrões de segurança e qualidade da construção.

De acordo com Ribeiro e Helene [2], patologia é a parte da engenharia que estuda os sintomas, as causas e os defeitos das construções.

As pontes, como qualquer outra edificação, também se deterioram com o passar do tempo e requerem cuidados para não se debilitarem e tornarem-se vulneráveis às ações de agentes ambientais endógenos ou exógenos [3]. Os agentes ambientais internos ou endógenos são aqueles agentes de transformação do relevo, que surgem de dentro da Terra. São exemplos destes agentes, terremotos, vulcanismos e tectonismos. Quanto aos agentes exógenos ou externos, são aqueles que agem acima da superfície. São as ações dos ventos, águas, intemperismo e dos seres vivo.s Os agentes ambientais endógenos e exógenos podem por em risco as suas condições de estabilidade e funcionalidade.

Por se tratar de estruturas, em sua maioria, com mais de 50 anos de construção e objeto principal de ligação entre bairros comerciais na cidade do Recife, ressalta-se a importância de alertar que os danos causados pelas manifestações patológicas nessas pontes podem acarretar em severos danos para a população e para a locomoção das pessoas entre estes bairros.

Este artigo tem como propósito colaborar para a disseminação do conhecimento das manifestações patológicas em estruturas de concreto armado encontradas em algumas pontes localizadas no Recife. Serão avaliadas estruturas como vigas, tabuleiros e guarda-corpo das pontes. Visando reforçar a importância da manutenção preventiva, de forma a garantir a vida útil dessas construções. $O$ resultado esperado com essa produção é alertar as consequências que essas problemáticas podem acarretar nas obras de infraestrutura.

\section{Método de pesquisa}

A metodologia utilizada neste estudo foi a revisão bibliográfica qualitativa sobre manifestações patológicas ocorridas sete pontes pontes do centro do Recife. Para - levantamento bibliográfico foram utilizados dados dos últimos 8 anos, nas bases Scielo e Lilac. Foram utilizados os seguintes termos: "manifestações patológicas 
PINHEIRO, M. R. A.; SILVA, E. I., CONSIDERAÇÕES A RESPEITO DAS PRINCIPAIS MANIFESTAÇÕES PATOLÓGICAS EM PONTES DE CONCRETO ARMADO NA CIDADE DE RECIFE. $3^{\circ}$ Simpósio Paranaense de Patologia das Construções (3० SPPC), artigo 3SPPC1020, pp. 220 - 232, 2018. DOI: 10.4322/2526-7248.020

pontes recife", manifestações patológicas recife ponte concreto recife", "pontes recife", "pontes concreto recife". Foram utilizados também livros, manuais e alguns parâmetros estabelecidos pela ABNT.

\subsection{Objeto de estudo}

Recife possui cerca de 49 pontes em utilização hoje. Dentre estas pontes, foram escolhidas 7 pontes localizadas no centro do Recife (Fig. 1), ligando os Bairros de São José, Recife Antigo, Santo Amaro e Boa Vista.

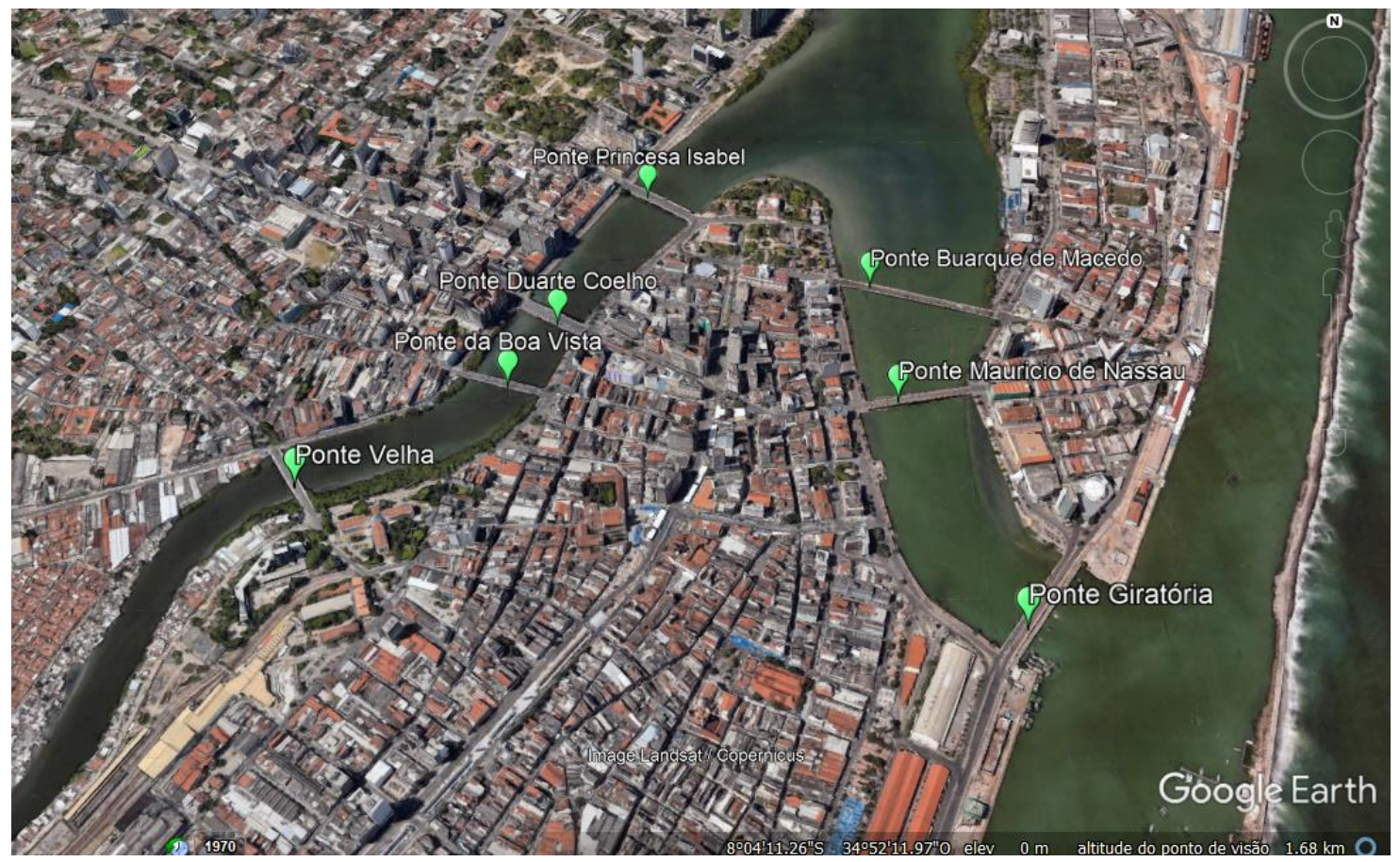

Figura 1: Pontes estudadas no presente trabalho

Fonte: Google Earth.

As pontes definidas para este trabalho, além de pontos turísticos são as principais vias de acesso entre bairros comerciais, por onde andam milhares de pessoas diariamente, são elas:

- Ponte Velha ou Ponte 6 de Março (1921) (Fig.2);

- Ponte da Boa Vista (1874) (Fig. 3);

- Ponte Duarte Coelho (1943) (Fig. 4);

- Ponte Santa Isabel ou Ponte Princesa Isabel (1863) (Fig. 5);

- Ponte Buarque de Macedo (1922) (Fig. 6);

- Ponte Mauricio de Nassau (1917) (Fig 7);

- Ponte Giratória (1971) (Figura 8). 
PINHEIRO, M. R. A.; SILVA, E. I., CONSIDERAÇÕES A RESPEITO DAS PRINCIPAIS MANIFESTAÇÕES PATOLÓGICAS EM PONTES DE CONCRETO ARMADO NA CIDADE DE RECIFE. $3^{\circ}$ Simpósio Paranaense de Patologia das Construções (30 SPPC), artigo 3SPPC1020, pp. 220 - 232, 2018. DOI: 10.4322/2526-7248.020

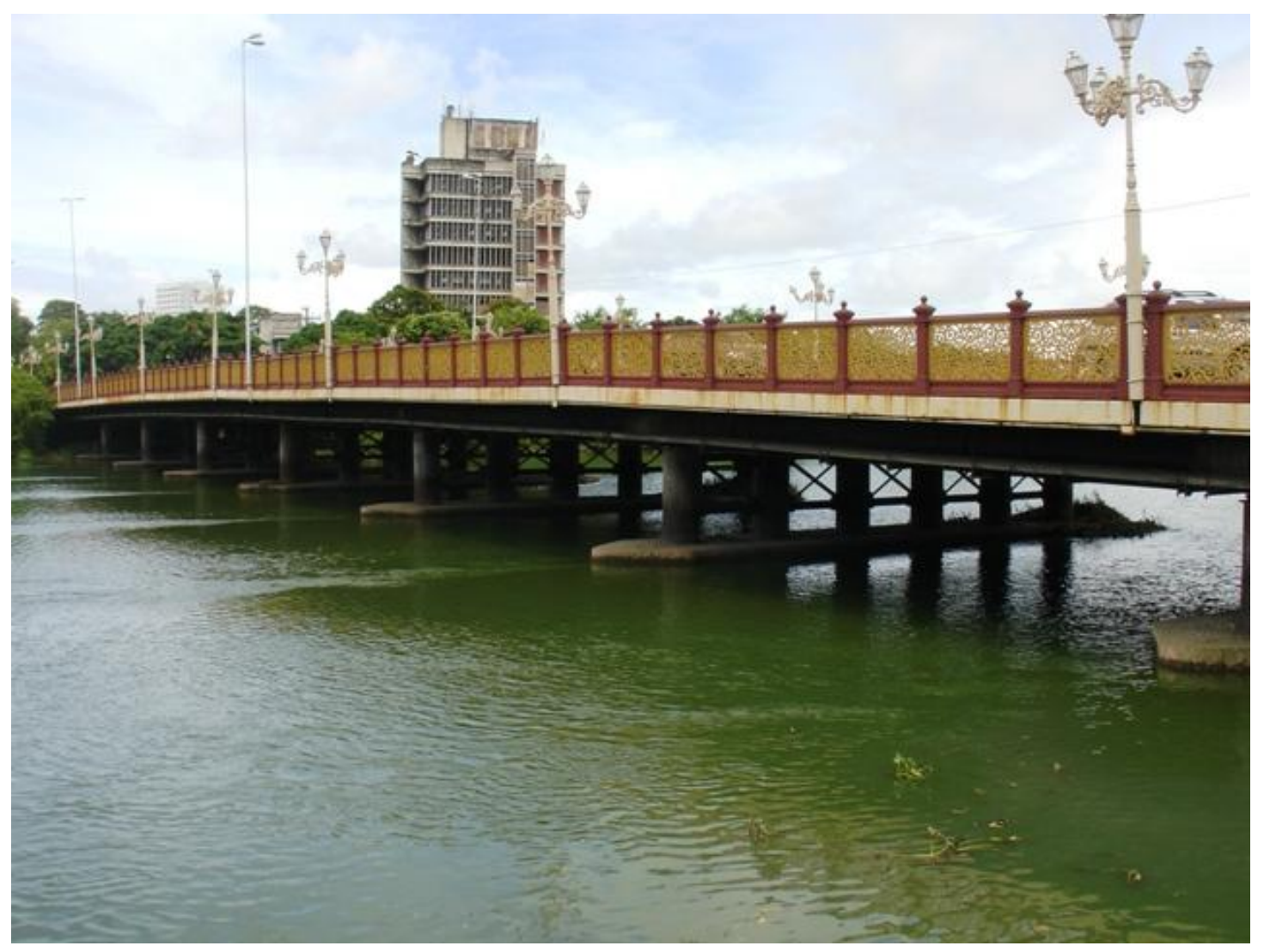

Figura 2: Ponte Velha ou Ponte 06 de Março

Fonte: Google.

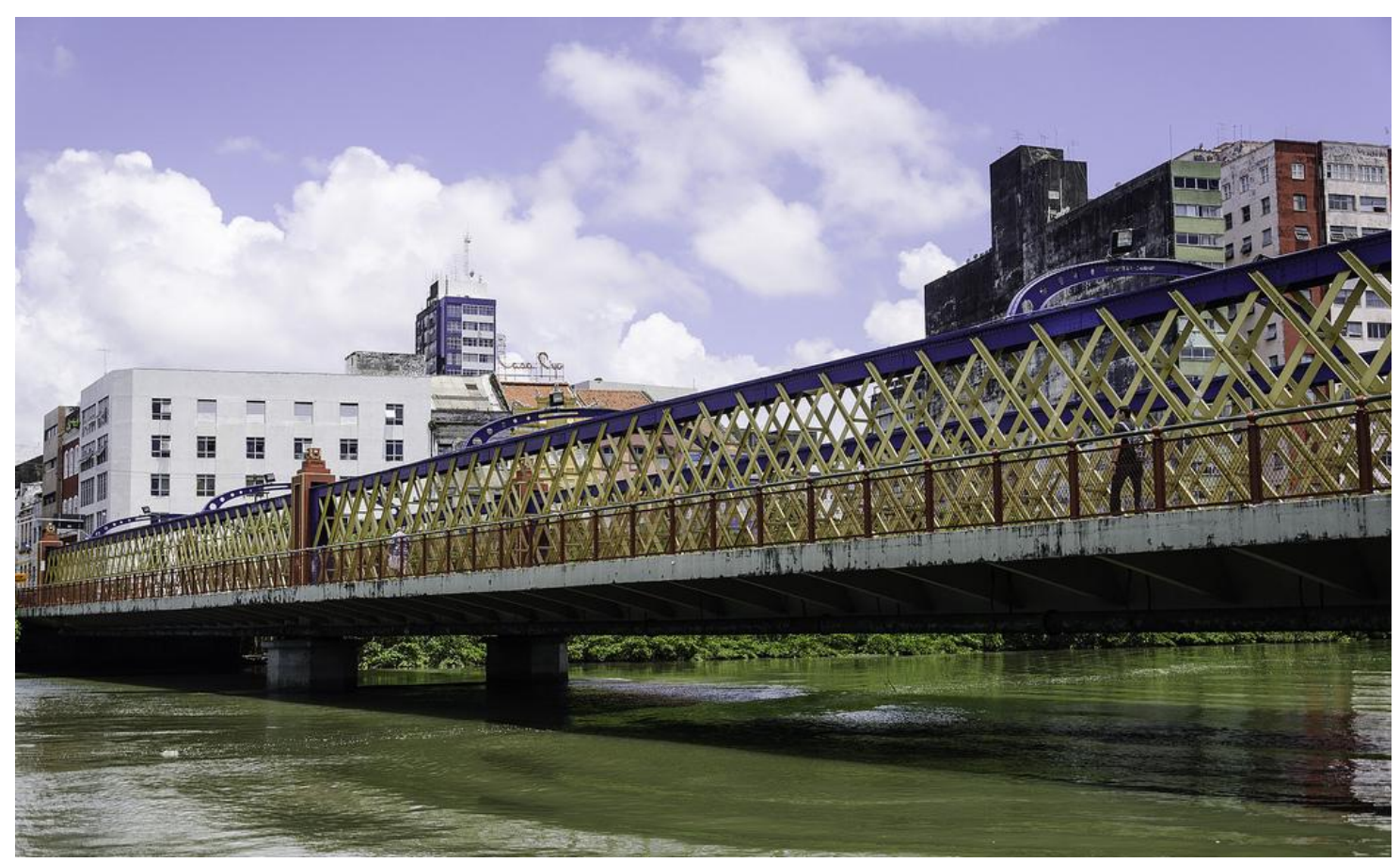

Figura 3: Ponte da Boa Vista

Fonte: Google. 
PINHEIRO, M. R. A.; SILVA, E. I., CONSIDERAÇÕES A RESPEITO DAS PRINCIPAIS MANIFESTAÇÕES PATOLÓGICAS EM PONTES DE CONCRETO ARMADO NA CIDADE DE RECIFE. $3^{\circ}$ Simpósio Paranaense de Patologia das Construções (30 SPPC), artigo 3SPPC1020, pp. 220 - 232, 2018. DOI: 10.4322/2526-7248.020

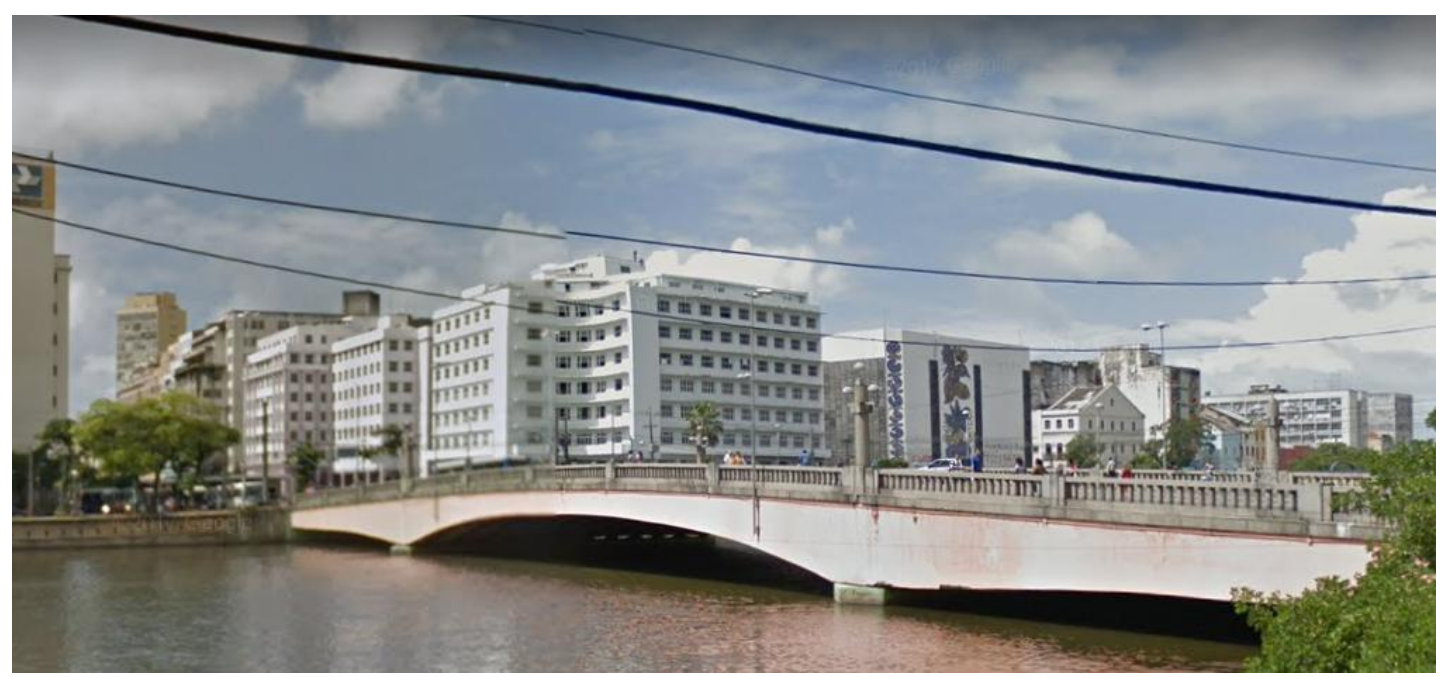

Figura 4: Ponte Duarte Coelho

Fonte: Google.

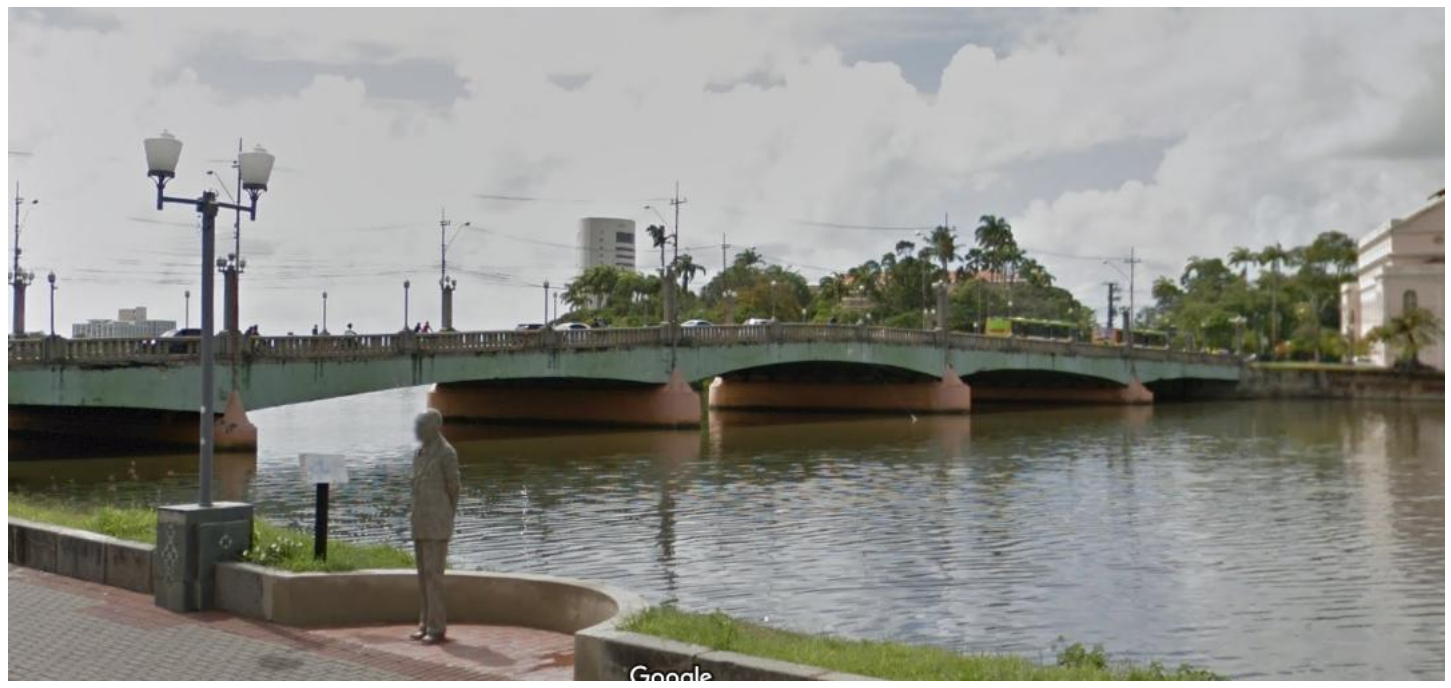

Figura 5: Ponte Princesa Isabel

Fonte: Google. 
PINHEIRO, M. R. A.; SILVA, E. I., CONSIDERAÇÕES A RESPEITO DAS PRINCIPAIS MANIFESTAÇÕES PATOLÓGICAS EM PONTES DE CONCRETO ARMADO NA CIDADE DE RECIFE. $3^{\circ}$ Simpósio Paranaense de Patologia das Construções (30 SPPC), artigo 3SPPC1020, pp. 220 - 232, 2018. DOI: 10.4322/2526-7248.020

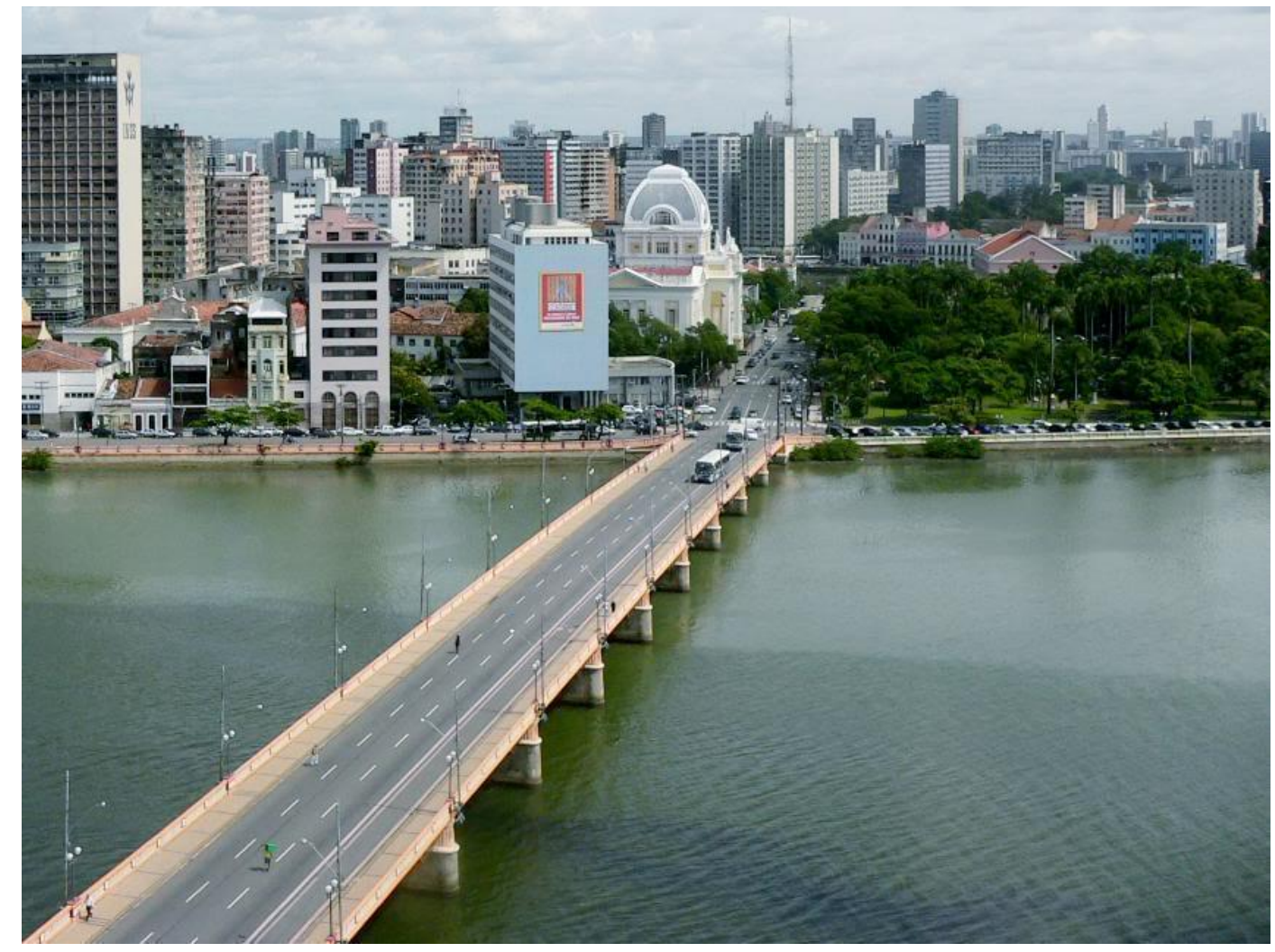

Figura 6: Ponte Buarque de Macedo

Fonte: Google.

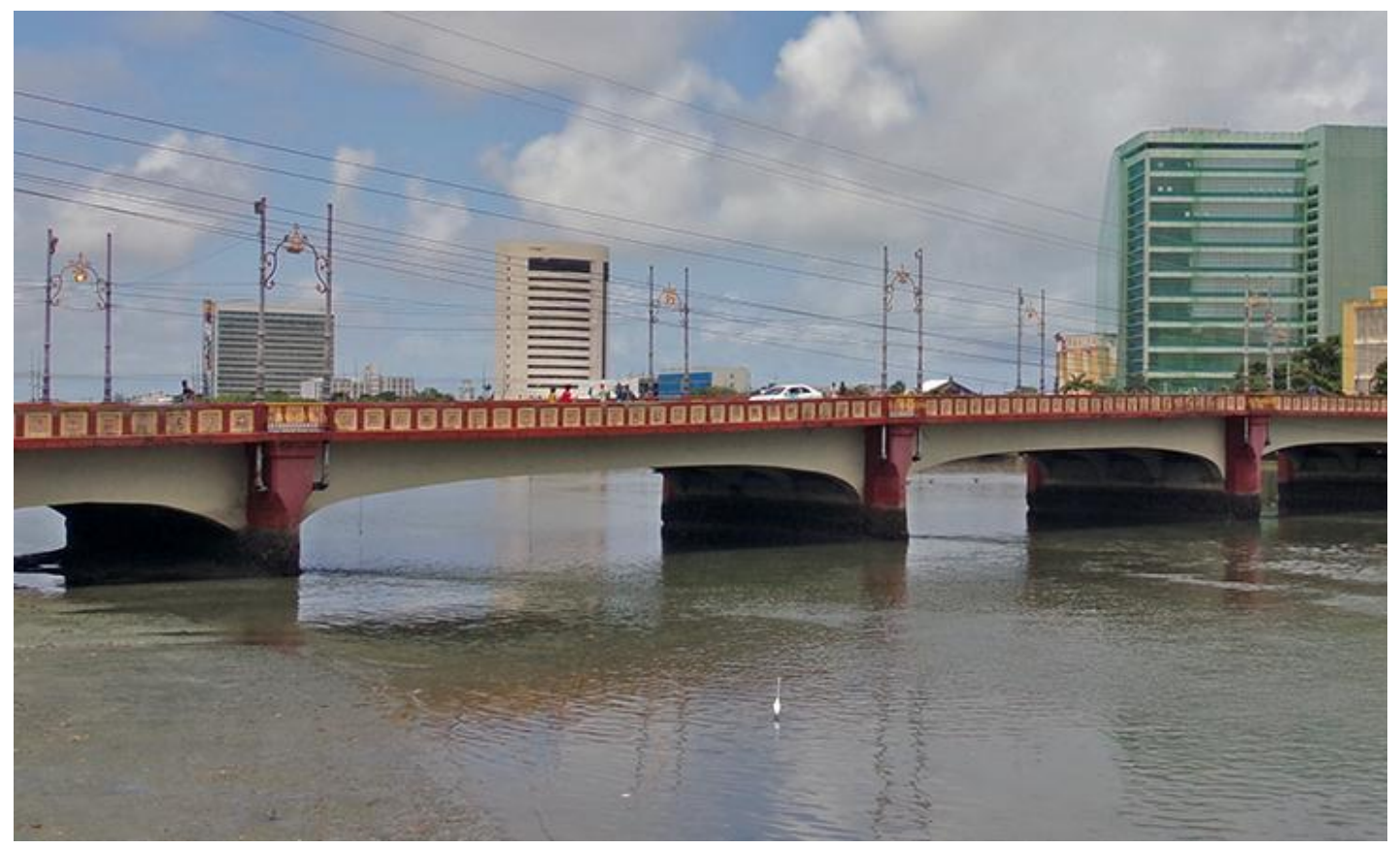

Figura 7: Ponte Mauricio de Nassau

Fonte: Google. 


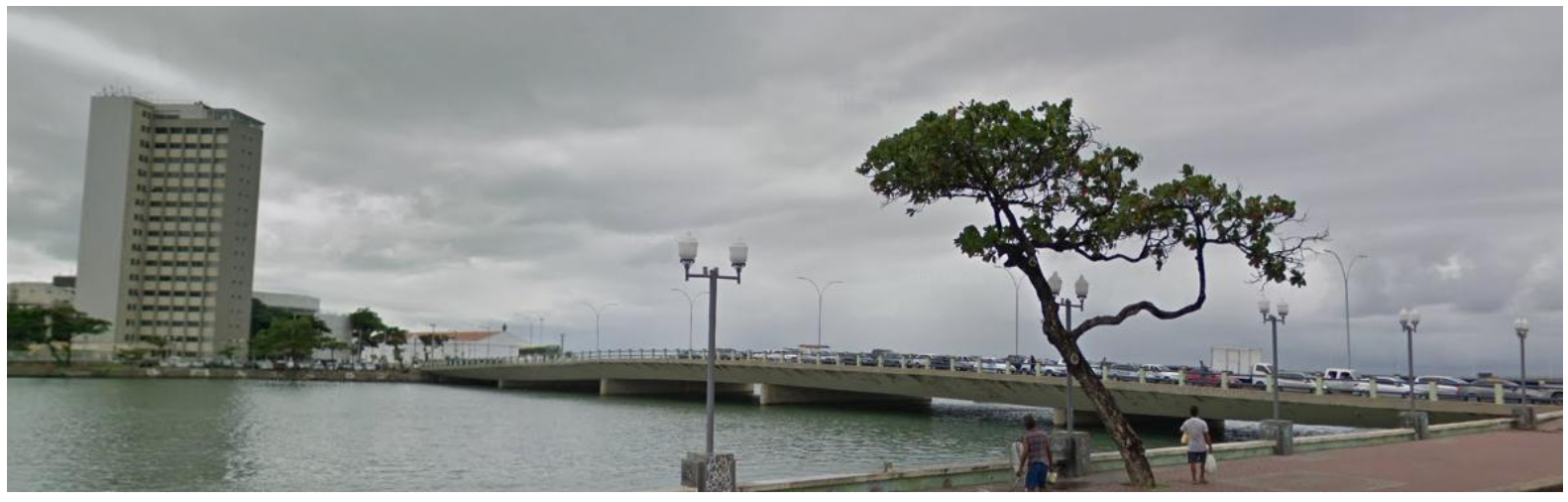

Figura 8: Ponte Giratória

Fonte: Google.

\section{As Manifestações Patológicas}

Recife, é uma cidade litorânea que tem como forte característica os seus recursos hídricos, que são muito abundantes. A cidade é banhada por três bacias hidrográficas, quais sejam: Capibaribe, Beberibe e Tejipió, sendo cortada pelos Rios Capibaribe e Beberibe além de outros de menor porte como o Jiquiá, Jordão e Tejipió, além de a leste ser banhada pelo Oceano Atlântico Sul [4]. Ademais, Recife possui inúmeros canais e pontes, e por isso é conhecida como a "Veneza brasileira".

As estruturas das pontes recifenses estão localizadas em um ambiente de classe de agressividade III [5], com risco alto de deterioração da estrutura. Por estar localizada em área próxima a ambiente marinho, ocorre na estrutura grande incidência de sais, que se depositam na superfície do concreto e podem penetrar na estrutura, ocasionando diversos tipos de manifestações patológicas [6].

Após a compilação de dados, foi realizado o levantamento das diversas manifestações patológicas que assolam essas estruturas. As principais problemáticas encontradas foram:

\subsection{Fissuras}

A fissura no concreto é uma fratura linear que pode se estender parcial ou completamente através do elemento. É uma manifestação que está relacionada a diferentes causas, como por exemplo, podendo ser através de materiais empregados de forma incorreta, ataques físicos (efeitos da temperatura) e ataques químicos (efeitos de substâncias presentes no ambiente). Estes efeitos podem progredir ao ponto de causar desplacamentos e até colapso da estrutura, dependendo de seu tamanho [6 - 8].

As fissuras podem ainda ser resultados secundários de outras manifestações, como o caso da corrosão de armadura que ao expandir, ocasiona a fissura no concreto, culminando no desplacamento. 
PINHEIRO, M. R. A.; SILVA, E. I., CONSIDERAÇÕES A RESPEITO DAS PRINCIPAIS MANIFESTAÇÕES PATOLÓGICAS EM PONTES DE CONCRETO ARMADO NA CIDADE DE RECIFE. $3^{\circ}$ Simpósio Paranaense de Patologia das Construções (3० SPPC), artigo 3SPPC1020, pp. 220 - 232, 2018. DOI: 10.4322/2526-7248.020

No estudo realizado por Cavalcanti et al [6], sobre as manifestações encontradas na Ponte Princesa Isabel foram encontradas diversas fissuras em diferentes pontos e com diferentes tamanhos (Fig. 9).
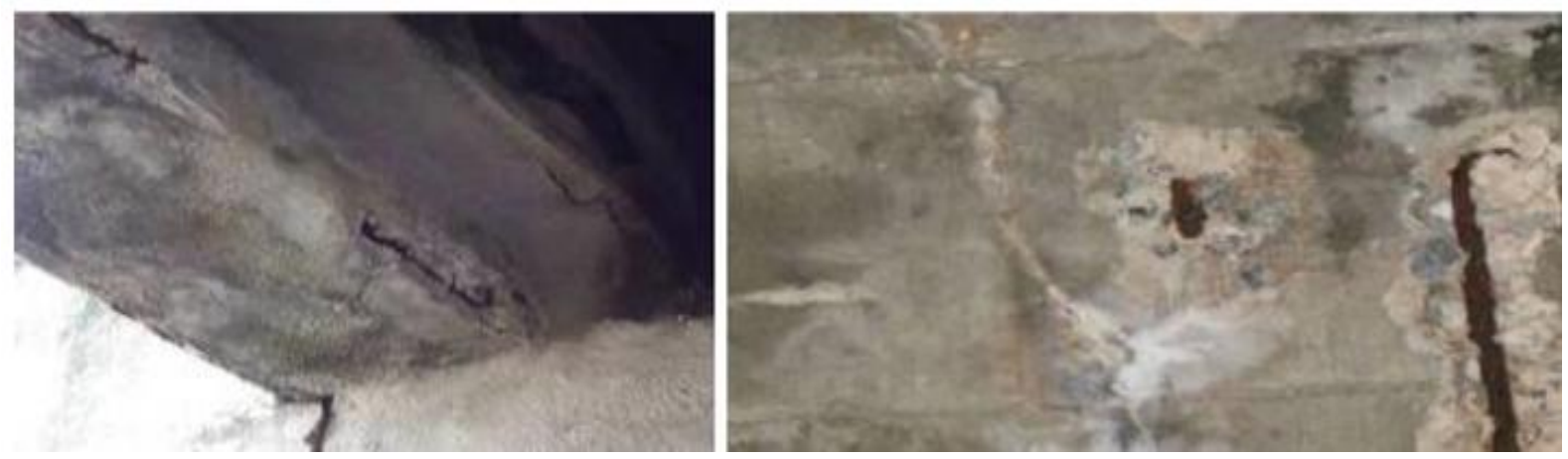

Figura 9: Fissuras em viga da Ponte Princesa Isabel [6]

\subsection{Desagregação do concreto}

A desagregação do concreto é ocorre quando ele perde sua propriedade aglomerante, ou seja, perde a capacidade de coesão. Com isto, ocorre a separação física do prórpiro concreto em frações, de modo que a estrutura acaba por perder a capacidade resistente a esforços na região desagregada [9].

A literatura aborda diferentes fatores que podem causar este tipo de manifestação patológica, entre eles estão: fissuração, movimentação das formas, corrosão do concreto, ataques biológicos, calcinação que consiste na perda de resistência e mudança de cor do concreto [9],[11].

Foram encontrados locais com ocorrência de desagregação do concreto nos vãos das pontes, especialmente nas regiões da face inferior das vigas (Fig. 10) [6]. Nos estudos de Aguiar et al. [11] percebe-se que essa manifestação também ocorre em outras pontes na região metropolitana recifense (Fig. 11).
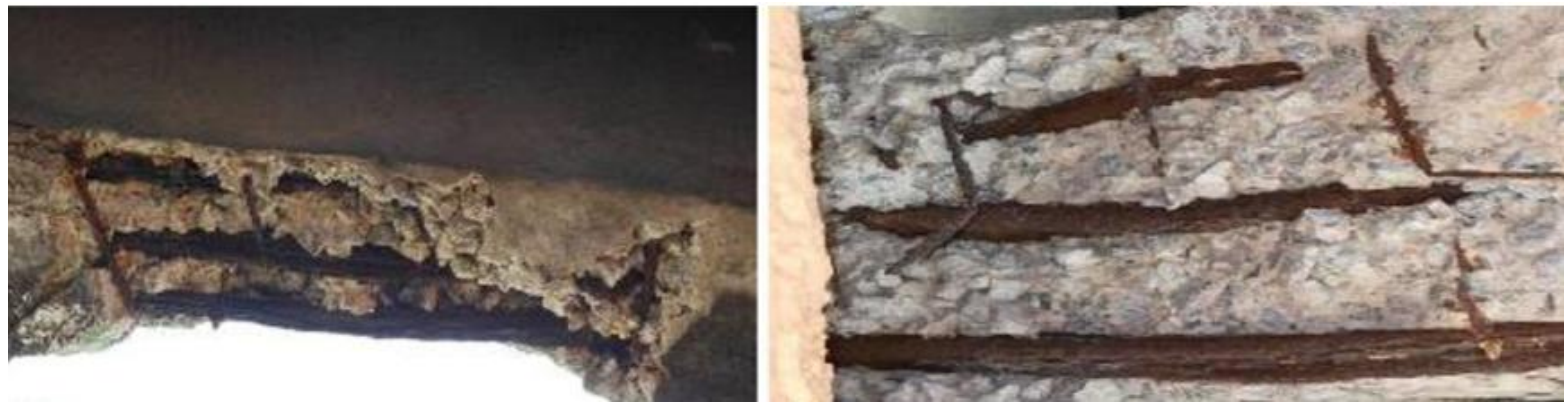

Figura 10: Partes da Ponte Princesa Isabel com desagregação do concreto [6] 


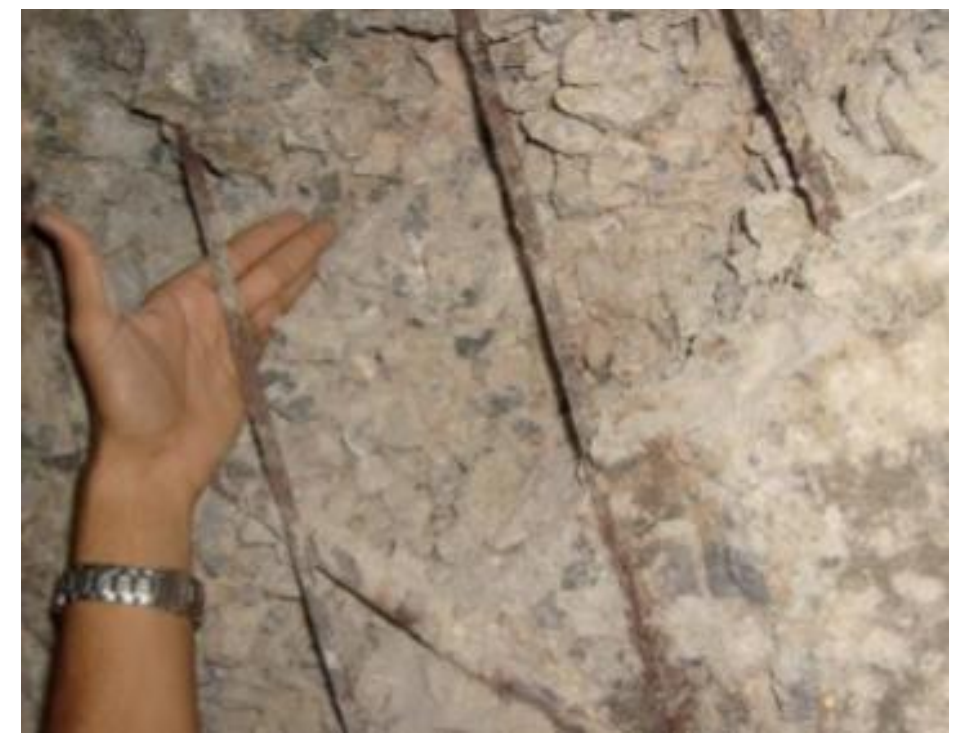

Figura 11: Vazios ocasionados pela desagregação do concreto na Ponte Duarte Coelho [11]

\subsection{Eflorescência}

Caracterizadas como formações salinas que surgem nas superfícies das estruturas, trazidas de seu interior pela umidade, apresentando como característica o aspecto esbranquiçado à superfície da estrutura [6],[10]. Um dos principais fatores para ocorrência da eflorescência é a alta umidade. A água da chuva ou do solo dissolve os sais presentes fazendo-os migrar para a superfície onde a evaporação da água ocasiona a formação dos depósitos salinos [10], [14].

Os estudos de Cavalcanti [6] trazem o ocorrência dessa manifestação patológica principal nas partes onde haviam furos no tabuleiro para suporte das tubulações (Fig. 12).

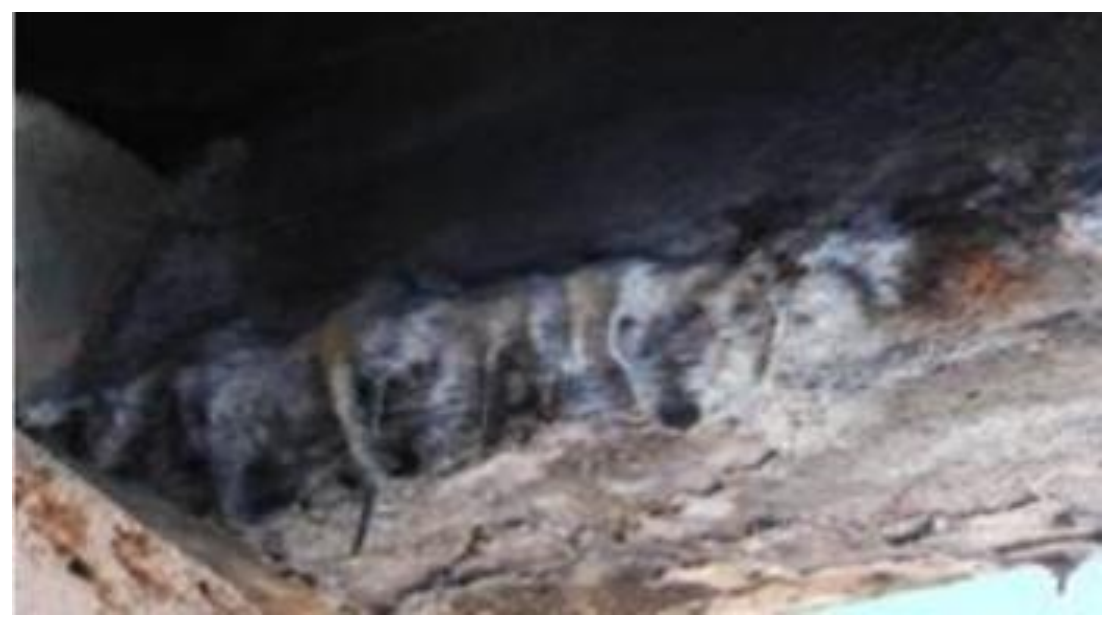

Figura 12: Presença de eflorescência nas vigas da da estrutura da Ponte Princesa Isabel [6] 


\subsection{Bolor e Limo}

Por se tratar de um ambiente úmido, a presença de bolores e limos são facilmente encontradas nas estruturas das pontes. Esses bolores são causados pela presença de fungos que se instalam em frestas e fissuras existentes, por causa da umidade e infiltração de água. As manchas encontradas apresentavam colorações esverdeadas e preto-esverdeadas, isso ocorre pela decomposição da matéria orgânica que serve de alimento aos fungos (Fig. 13 e 14) [6],[11].

Os limos observados tratam-se de vegetais microscópicos que se alimentam de substâncias existentes na água infiltrada [6].

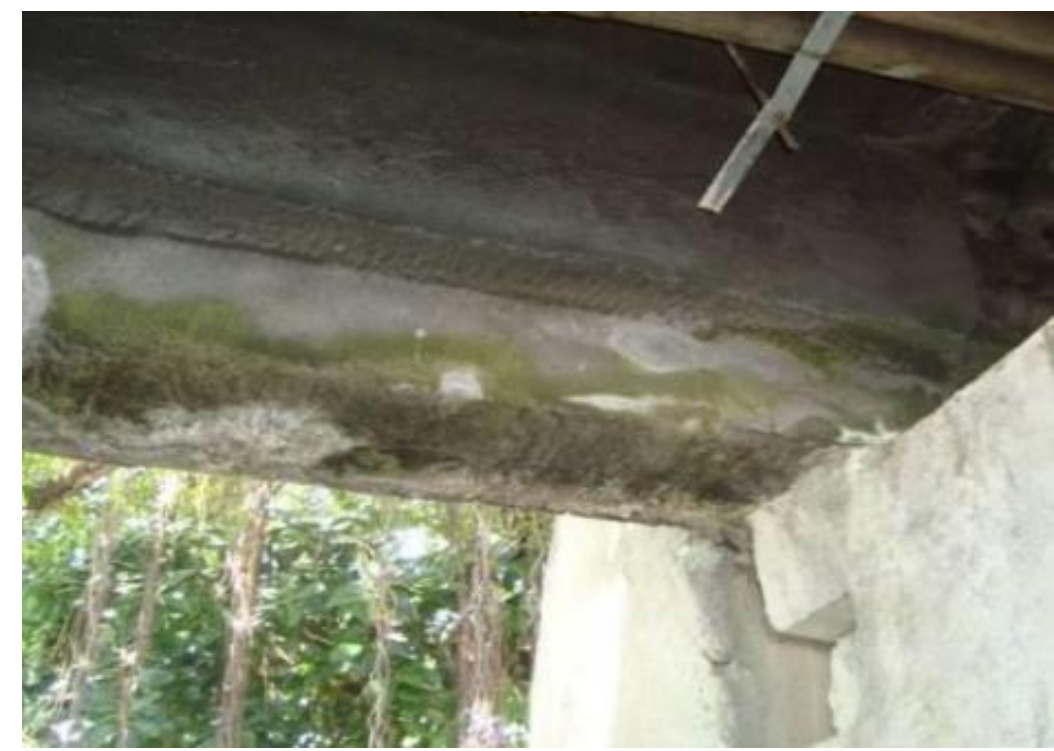

Figura 13: Presença de bolores na estrutura da Ponte Princesa Isabel [6]

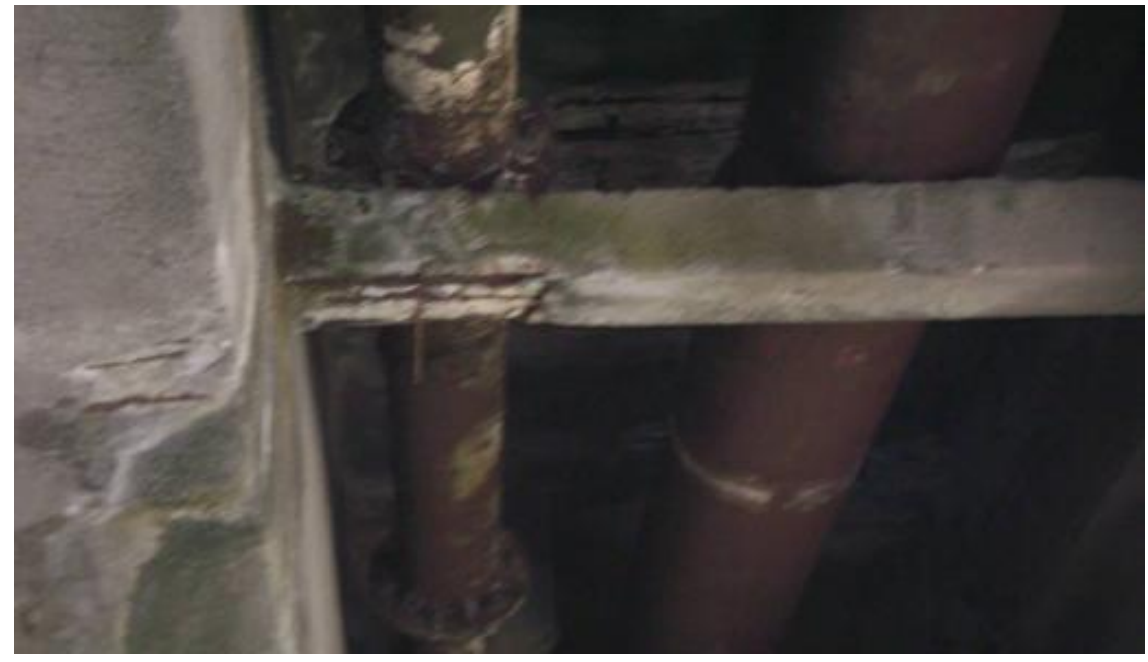

Figura 14: Presença de bolores e limbo na Ponte Duarte Coelho [11]

\subsection{Corrosão de armadura}

A corrosão das armaduras de concreto são consideradas um fenômeno de natureza eletroquímica que pode ser acelerado pela presença de agentes químicos externos 
PINHEIRO, M. R. A.; SILVA, E. I., CONSIDERAÇÕES A RESPEITO DAS PRINCIPAIS MANIFESTAÇÕES PATOLÓGICAS EM PONTES DE CONCRETO ARMADO NA CIDADE DE RECIFE. $3^{\circ}$ Simpósio Paranaense de Patologia das Construções (3० SPPC), artigo 3SPPC1020, pp. 220 - 232, 2018. DOI: 10.4322/2526-7248.020

ou internos ao concreto [2]. Os agentes externos podem ser: ação dos ventos ou da água do mar. Os agentes internos, por exemplo, podem ser: Betão pouco compacto com excesso de água ou insuficiência de vibração do betão, entre outros.

Esta manifestação pode se apresentar através de manchas superficiais, fissuras, destacamento do concreto, redução da seção existente das armaduras, entre outras consequências [4-6].

A corrosão de armaduras foi bastante encontrada na inspeção visual (Fig. 15 e Fig. 16), provavelmente devido à estrutura estar inserida na CAA III (classe de agressividade III) de acordo com a NBR 6118 [4].

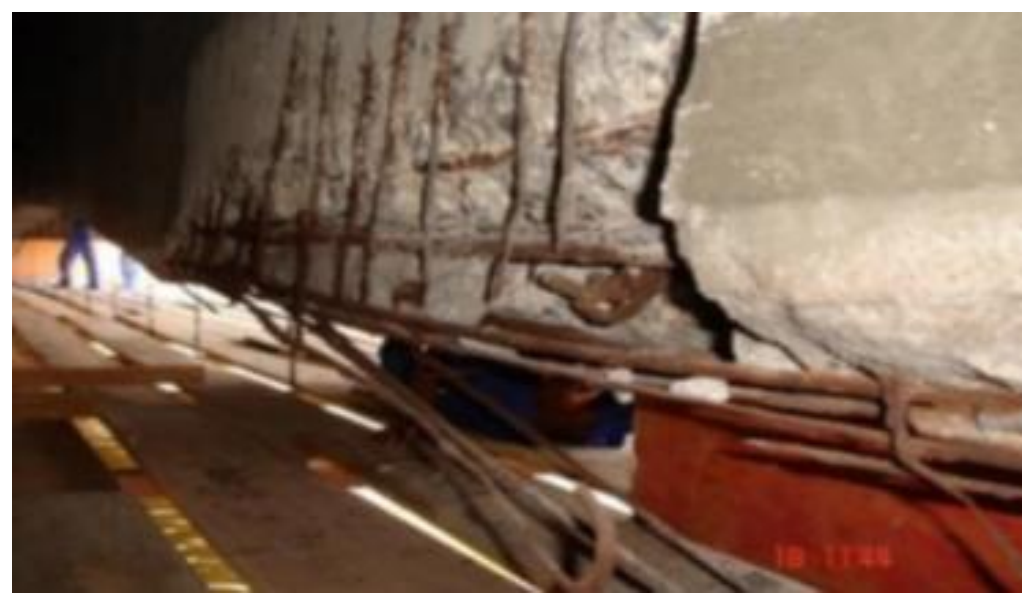

Figura 15: Corrosão da armadura presente nas Ponte Buarque de Macedo [11]

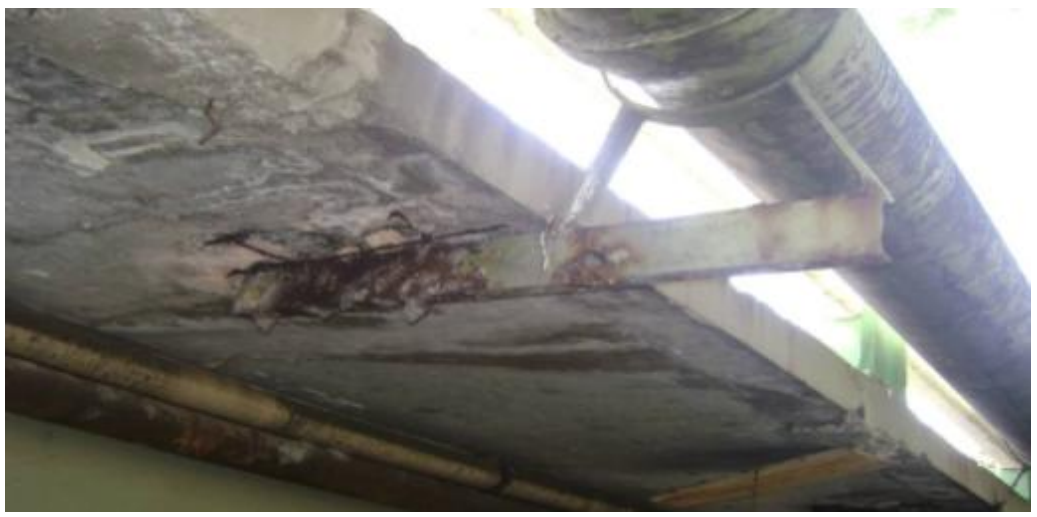

Figura 16: Tubulação apoiada no tabuleiro e fixada na face inferior da laje, na Ponte Giratória [12]

\section{Considerações Finais}

De acordo com o levantamento bibliográfico realizado foi verificada a existência de diversas manifestações patológicas nas pontes localizadas em Recife.

Essas manifestações podem ter sido provocadas pelo uso de materiais inadequados às condições da estrutura, falta de conhecimento do meio técnico durante a execução do projeto e da construção e, falhas construtivas, precárias manutenções das estruturas ao longo dos anos e a intensa agressividade do meio ambiente em que se localiza a ponte. 
PINHEIRO, M. R. A.; SILVA, E. I., CONSIDERAÇÕES A RESPEITO DAS PRINCIPAIS MANIFESTAÇÕES PATOLÓGICAS EM PONTES DE CONCRETO ARMADO NA CIDADE DE RECIFE. $3^{\circ}$ Simpósio Paranaense de Patologia das Construções (3० SPPC), artigo 3SPPC1020, pp. 220 - 232, 2018. DOI: 10.4322/2526-7248.020

É importante promover ações regulares de recuperação dessas pontes, a fim de garantir a vida útil dessas estruturas. Por se tratarem de pontes construídas há mais de 50 anos, reforça-se ainda a importância cultural e de mobilidade que essas pontes representam para a cidade.

É importante também promover a consciência de que a manutenção preventiva é uma ação necessária que deve ser feita com regularidade. E que se não houver intervenções de forma rápida, a tendência é aumentar as minfestações e, em caso extremo, culminar em colapso.

\section{Referências}

[1] Santos, A. G. F. S.; Sousa, A. O.; Farias, M. L. A.; Pontes, V. F. J. (2017) Levantamento de manifestações patológicas de uma ponte de concreto armado junto a suas possíveis técnicas de recuperação. In: Conferência Nacional de Patologia e Recuperação de Estruturas - Conpar, Recife, Brasil.

[2] Ribeiro, D. V. e Helene, P. (2014) Corrosão em Estruturas de Concreto Armado. "Teoria, Controle e Métodos de Análise" - 1ำedição - Rio de Janeiro, editora CAMPUS,

[3] Vitório, J. A. P. (2015) Pontes e viadutos rodoviários: conceituação, conservação, segurança e reforço estrutural. Recife: Escola Politécnica da Universidade de Pernambuco. (Apostila).

[4] Barros, H. R.; Lombardo, M. A. (2013) Zoneamento climático urbano da cidade do Recife: uma contribuição ao planejamento urbano. GEOUSP - Espaço e Tempo, São Paulo, № 33.

[5] NBR 6118 (2014). Projeto e execução de obras de concreto armado: procedimento. Associação Brasileira de Normas Técnicas - ABNT, Rio de Janeiro, Brasil.

[6] Cavalcanti, M.; Andrade, G.; Fonseca, J.; Oliveira, A.; Monteiro, E. (2016) Análise das manifestações patológicas da Ponte Princesa Isabel - estudo de caso. In: Conferência Nacional de Patologia e Recuperação de Estruturas Conpar, Recife, Brasil.

[7] Manual de Inspeção de Pontes Rodoviárias (2004) Departamento Nacional de Infraestrutura de Transportes - DNIT. Diretoria de Planejamento e Pesquisa. Coordenação do Instituto de Pesquisas Rodoviárias. 2 ed. Rio de Janeiro, 2004. 253p.

[8] Manual de Recuperação de Pontes e Viadutos Rodoviários (2010) Departamento Nacional de Infraestrutura de Transportes - DNIT. Diretoria Executiva. Instituto de Pesquisas Rodoviárias. Rio de Janeiro. 159p.

[9] Souza, V. C.; Ripper, T. (1998) Patologia, recuperação e reforço de estruturas de concreto. São Paulo: Pini. 255 p.

[10]Pintan, N. M. (2013) Manifestações Patológicas e Estudo da Corrosão Presente em Pontes do Recife. Dissertação (mestrado). Universidade Politécnica de Pernambuco - UPE. Recife. 
PINHEIRO, M. R. A.; SILVA, E. I., CONSIDERAÇÕES A RESPEITO DAS PRINCIPAIS MANIFESTAÇÕES PATOLÓGICAS EM PONTES DE CONCRETO ARMADO NA CIDADE DE RECIFE. $3^{\circ}$ Simpósio Paranaense de Patologia das Construções (3० SPPC), artigo 3SPPC1020, pp. 220 - 232, 2018. DOI: 10.4322/2526-7248.020

[11]Aguiar, M. S.; Silva, C. B. A.; Monteiro, E. C. B.; Lordsleem Jr., A. C. (2016) Inspeção e reabilitação em pontes de concreto - estudo de caso da Ponte Duarte Coelho. In: Seminário de Patologia e Recuperação Estrutural SEMIPAR, Recife, Brasil.

[12] Vitório, J. A. P.; Lins Neto, F. (2010) Patologias causadas por tubulações nas estruturas de pontes e viadutos. In: Anais do 52 Congresso Brasileiro do Concreto - CBC 2010 - 52 CBC.

[13] Stanton, T. E. (1940) Expansion of concrete through reaction between cement and aggregate. In: Proceedings of American Society of Civil Engineers. v. 66, n. 10. Dec.

[14] Fonseca, J. M. M.; Silva, D. L.; Sampaio, R. G. M.; Monteiro, E. C. B. (2016) Ação deletéria no concreto em decorrência da reação álcali-agregado. Revista Unipam, Minas Gerais, Brasil. 